\title{
Organoleptic Properties, Proximate Compositions, and Antioxidant Activity of Carrot - Navel Orange Marmalade
}

\author{
Dzul Fadly ${ }^{1 *}$ (D), Nur Afni Rahmatiya Abdul ${ }^{2} \mathbb{D}$, Yuges Saputri Muttalib ${ }^{2}$, Bohari Bohari ${ }^{3} \mathbb{D}$ \\ ${ }^{1}$ Department of Food Technology, Faculty of Agriculture, Tanjungpura University, Pontianak, Indonesia; ${ }^{2}$ Department of Nutrition, \\ Faculty of Health Sciences, Esa Unggul University, Jakarta, Indonesia; ${ }^{3}$ Department of Nutrition, Faculty of Medicine, Sultan \\ Ageng Tirtayasa University, Serang, Indonesia
}

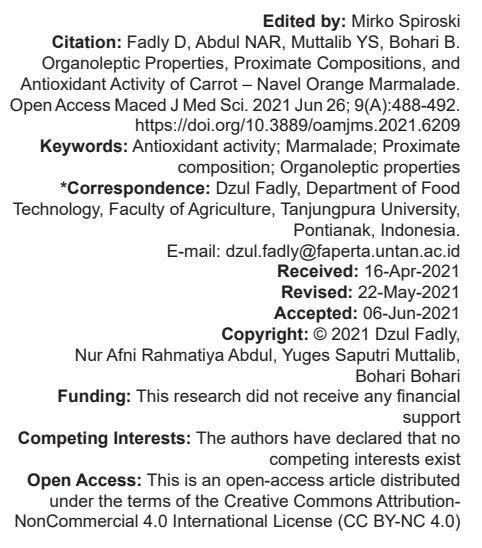

\section{Introduction}

Free radicals are components that are harmful to the body. Radicals can oxidize both fat in the human body and other living things, including food ingredients. Several causes of the radical's generation are ultraviolet rays, oxygen, heating, and others. In the human body, there are free radicals that might cause oxidative damage. Imbalances between free radicals such as reactive oxygen species with antioxidant activity lead to oxidative stress [1]. Prolong oxidative stress due to the excess of free radicals might trigger cellular damage and cause degenerative diseases. This process becomes the etiology and initiates various degenerative chronic diseases, such as diabetes mellitus, inflammation, coronary heart disease, and cancer [2], [3], [4].

Antioxidants are very beneficial for health in preventing the aging process and degenerative diseases. The excess free radicals generated in the body may overwhelm natural cellular antioxidant defenses and contribute to cellular functional impairment.
Antioxidants will act as free radicals scavenging and protect other molecules in the cells from oxidation damage by free radicals or reactive oxygen [5]. Their capability in neutralizing the free radicals may reflect the phytochemical compounds, including phenolics and flavonoids [6]. Those compounds would scavenge free radicals by donating $\mathrm{H}^{+}[7]$.

Nowadays, people tend to back to nature lifestyle. They choose to improve the used natural compounds than chemical or synthetic compounds. Various antioxidants obtained from natural ingredients are currently used to enhance antioxidant intake through functional food development. Functional food refers to a product consumed in the food form, not pills, capsules, or any other dosages [8]. Carrots and navel oranges are known as high antioxidant sources. It may are potent to develop to be functional food with high antioxidant activity. Those fruit and vegetables are easy to process into various home food products, also available almost in local markets, both developed or developing countries. Marmalade is a preserved food made from fruit juice. It has a semi-solid texture 
with sucrose, citric acid, pectin, and pieces of fruit skin (albedo). The manufacture of jam, jelly, or marmalade was rarely used vegetables as raw materials. This study aimed to formulate a carrot-navel orange marmalade and determine the organoleptic properties, proximate compositions, and antioxidant activity.

\section{Materials and Methods}

\section{Product formulations}

This study was an experiment with a completely randomized design. The main ingredients used were carrots and navel oranges. All of the ingredients used were gathered from a local market in Jakarta, Indonesia. All the products formulated were sorted and cleaned before formulated into marmalade products. There were five formulations of marmalade, which are displayed in Table 1. The products were then submitted to Saraswati Indo Genetech Laboratory, Bogor, for further analysis.

Table 1: Product formulations

\begin{tabular}{llllll}
\hline Ingredients & \multicolumn{3}{l}{ Formulations } & & \\
\cline { 2 - 6 } & F1 & F2 & F3 & F4 & F5 \\
\hline Navel orange (g) & 100 & 100 & 100 & 100 & 100 \\
Carrot (g) & 0 & 25 & 50 & 75 & 100 \\
Lemon water (ml) & 15 & 15 & 15 & 15 & 15 \\
Pectin (g) & 3 & 3 & 3 & 3 & 3 \\
sugar (g) & 60 & 60 & 60 & 60 & 60 \\
\hline
\end{tabular}

The main ingredients used as a primary ingredient were navel orange and carrot. The usage of navel orange in this study was in high concentration and remained the same in all formulations. The carrot was used as a factor affecting the product with different amounts of addition. Then, lemon water, pectin, and sugar were used as complementary ingredients used in small and remained the same amount in each formulation.

Product manufacturing was including some steps, such as juices preparation, carrot and orange peels shreds preparation, and marmalade making. The juices made by: Carrots were chopped by food processor "Chopper Philips HR-2939 N" and then filtered, while oranges were cut and squeezed. The shreds preparation was done by cleaning the carrot and orange; blanched for about 2-3 min; carrot and orange peels were finely shredded. As the last steps, marmalade was produced by mix both juice with lemon, sugar, and pectin, stirred evenly. Heated the mixture to temperature $70^{\circ} \mathrm{C}$ while stirring until forming a gel; turn off the stove; added the shreds of carrots and oranges peels. The total amount of carrots and orange used was divided into $50 \%$ juice and $50 \%$ shreds for each formulation.

\section{Organoleptic properties assessment}

About 25 semi-trained panelists assessed the organoleptic properties of marmalade products.
The assessment was executed using a visual analog scale; with the scale used was 0-10. The tests included hedonic (color, aroma, taste, texture, and overall) to analyze sensory acceptance and hedonic quality (color, aroma, taste, texture, and overall) characteristics. Hedonic parameters measured from 0 to 10 (dislike very like) for all parameters. Hedonic quality parameters measured from 0 to 10 for color (very bright orange - very dark orange), aroma (very unpleasant - very pleasant), taste (very bitter - very sweet), texture (very liquid - very thick), and overall (very unattractive - very attractive).

\section{Proximate composition and Brix determination}

Proximate compositions were determined by AOAC methods, sub-components of 925.09 (moisture), 923.03 (total ash), 979.09 (crude protein), 962.09 (crude fiber), and 920.29 (fat) [9]. Carbohydrate content was determined by difference calculation [10]. The Brix measured by refractometer [11].

\section{Antioxidant activities determination}

The 1,1-Diphenyl-2-picrylhydrazyl (DPPH) measurement was executed with slight modification Molyneux [12]. About $100 \mu \mathrm{L}$ samples $(0.62-4.96 \mathrm{mg} / \mathrm{mL})$ or $19 \%$ ethanol or ascorbic acid (as standard) mixed with $50 \mu \mathrm{L} 100 \mathrm{mM}$ Tris $-\mathrm{HCl}$ (pH 7.4) and then added with $5 \mu \mathrm{L} 500 \mathrm{M}(2.5 \mathrm{mg} /$ $\mathrm{mL}$ ) DPPH. About $90 \%$ of ethanol used as a blank solution, and the DPPH solution without samples was presented as a control. The mixture was then shaken vigorously for 1-3 $\mathrm{min}$ and allowed to stand at room temperature for $30 \mathrm{~min}$ in dark conditions. The absorbance of the solution was measured using a spectrophotometer with a wavelength of $517 \mathrm{~nm}$. Antioxidant activity is expressed as $\mathrm{IC}_{50}$ (half maximal inhibitory concentration). The formula calculates the percentage of free radical inhibitory:

Inhibition $(\%)=\frac{\text { Blank absorbancy }- \text { sample absorbancy }}{\text { Blank absorbancy }} \times 100$

\section{Data analysis}

Data were managed using Microsoft excel 365 for windows. SPPS version 20.0 for windows from SPSS Institute Inc., Cary, NC, was used for statistical analysis. The data of organoleptic and proximate composition were analyzed by one-way ANOVA test and separated by Duncan multiple-range tests at $p=0.05$. 


\section{Results and Discussion}

\section{Organoleptic properties}

Organoleptic properties were determined by sensory evaluation toward hedonic and hedonic quality measurements. The result of our organoleptic assessment results is summarized in Table 2. We evaluated the hedonic and hedonic quality of five products. The result of hedonic parameters showed significant differences $(p<0.05)$ on texture, and the hedonic quality obtained substantial differences $(p<0.05)$ on color, taste, and texture.

Table 2: Organoleptic values of carrot - navel orange marmalade

\begin{tabular}{cllllll}
\hline Parameters & \multicolumn{7}{l}{ Formulations (mean \pm SD } & & p-value \\
\cline { 2 - 5 } & F1 & F2 & F3 & F4 & F5 & \\
\cline { 1 - 4 } Hedonic & & & & & & \\
Color & $4.80 \pm$ & $6.50 \pm$ & $6.50 \pm$ & $6.60 \pm$ & $6.50 \pm$ & 0.06 \\
& 1.94 & 1.45 & 1.92 & 1.12 & 1.31 & \\
Aroma & $5.34 \pm$ & $5.55 \pm$ & $5.45 \pm$ & $6.07 \pm$ & $5.45 \pm$ & 0.56 \\
& 1.36 & 1.88 & 2.03 & 1.32 & 1.57 & \\
Taste & $5.70 \pm$ & $6.50 \pm$ & $6.30 \pm$ & $5.90 \pm$ & $6.80 \pm$ & 0.75 \\
& 1.86 & 1.69 & 1.52 & 1.45 & 1.87 & \\
Texture & $5.86 \pm$ & $6.57 \pm$ & $6.19 \pm$ & $6.18 \pm$ & $5.16 \pm$ & 0.04 \\
& $1.85^{\mathrm{a}, \mathrm{b}}$ & $1.39^{\mathrm{b}}$ & $1.89^{\mathrm{b}}$ & $1.35^{\mathrm{b}}$ & $1.67^{\mathrm{a}}$ & \\
Overall & $5.95 \pm$ & $6.53 \pm$ & $6.37 \pm$ & $6.23 \pm$ & $5.93 \pm$ & 0.47 \\
& 1.27 & 1.41 & 1.58 & 1.22 & 1.44 & \\
Hedonic quality & & & & & & \\
Color & $6.20 \pm$ & $5.50 \pm$ & $6.60 \pm$ & $7.10 \pm$ & $7.00 \pm$ & 0.03 \\
& $2.06^{\mathrm{a}, \mathrm{b}}$ & $2.13^{\mathrm{a}}$ & $2.37^{\mathrm{a}, \mathrm{b}}$ & $1.42^{\mathrm{b}}$ & $1.26^{\mathrm{b}}$ & \\
Aroma & $5.78 \pm$ & $5.45 \pm$ & $5.50 \pm$ & $6.03 \pm$ & $5.52 \pm$ & 0.64 \\
& 1.33 & 1.73 & 1.87 & 1.12 & 1.55 & \\
Taste & $6.97 \pm$ & $6.84 \pm$ & $6.56 \pm$ & $7.26 \pm$ & $6.07 \pm$ & 0.02 \\
& $1.47^{\mathrm{b}}$ & $1.12^{\mathrm{a}, \mathrm{b}}$ & $1.53^{\mathrm{a}, \mathrm{b}}$ & $1.22^{\mathrm{b}}$ & $1.26^{\mathrm{a}}$ & \\
Texture & $6.80 \pm$ & $7.30 \pm$ & $7.50 \pm$ & $6.60 \pm$ & $5.50 \pm$ & 0.00 \\
& $1.65^{\mathrm{b}, \mathrm{c}, \mathrm{d}}$ & $1.53^{\mathrm{b}, \mathrm{c}, \mathrm{d}}$ & $1.33^{\mathrm{d}}$ & $1.34^{\mathrm{b}, \mathrm{c}}$ & $1.81^{\mathrm{a}}$ & \\
Overall & $6.00 \pm$ & $6.84 \pm$ & $6.71 \pm$ & $6.52 \pm$ & $5.97 \pm$ & 0.13 \\
& 1.60 & 1.40 & 1.82 & 1.17 & 1.38 & \\
\hline The numbers followed by different superscript letters in the same row represent significantly different values
\end{tabular}

$(p \leq 0.05)$. The parameters measured from 0 to 10

The color of marmalade was ranged from bright orange to dark orange. The more carrots added, the darker the marmalade produced. The brighter color generated was due to the lower addition of the carrot seems to decrease sensory acceptance. Carrots contain beta-carotene, while navel orange is also composed of the carotenoid compound, the type of pigment responsible for the orange color, which influenced the color of food products [13]. Volatile compounds in citrus fruits play an important role in shaping the odor and flavor. Oranges have a distinctive citrus fruit odor [14]. Some of the volatile components of the orange flavors are ethanol, octanol, nonanal, citral, ethyl butanoate, d-limonene, and a-pinene [15]. The addition of carrot decreased the sourness of navel orange marmalade, and the texture of marmalade was influenced by pectin compounds used for a gel-forming synthesis in the manufacture of marmalade.

The addition of the carrot had a significant impact on the organoleptic values. This addition may improve sensory acceptances (hedonic). It can be identified from the value of $\mathrm{F} 1$ ( $0 \%$ carrots) obtained the lowest value, among others, in all hedonic parameters. According to the sensory evaluation conducted by the 25 semi-trained panelists, it was revealed that the hedonic or sensory acceptance, marmalade F2 (25\% carrot) dedicated as the most acceptable product, among others. Product F2 had a medium bright color, quite pleasant aroma, a little sweet, quite thick texture, and quite attractive.

\section{Proximate compositions and brix}

The assessments on proximate parameters were conducted on carbohydrate, protein, fat, water, ash, and fiber, while ${ }^{\circ}$ Brix sugar was also measured. The result obtained is displayed in Table 3. The addition of carrots into navel orange marmalade significantly influenced the proximate parameters, that is, carbohydrate, protein, fat, water, ash, and fiber $(p<0.05)$.

Table 3: Proximate composition and Brix of carrot - navel orange marmalade

\begin{tabular}{lllllll}
\hline Parameters & \multicolumn{7}{l}{ Formulation (mean \pm SD) } & p-value \\
\cline { 2 - 6 } & F1 & F2 & F3 & F4 & F5 & \\
\hline Carbohydrate (\%) & $76.04 \pm$ & $73.27 \pm$ & $71.02 \pm$ & $74.48 \pm$ & $70.52 \pm$ & 0.000 \\
& $0.13^{\mathrm{d}}$ & $0.43^{\mathrm{b}}$ & $0.77^{\mathrm{a}}$ & $0.20^{\mathrm{c}}$ & $0.46^{\mathrm{a}}$ & \\
Protein (\%) & $3.10 \pm$ & $3.15 \pm$ & $3.64 \pm$ & $3.21 \pm$ & $3.00 \pm$ & 0.000 \\
& $0.02^{\mathrm{a}, \mathrm{b}}$ & $0.06 \mathrm{~b}$ & $0.01^{\mathrm{c}}$ & $0.00^{\mathrm{b}}$ & $0.10^{\mathrm{a}}$ & \\
Fat (\%) & $<0.02$ & $<0.02$ & $<0.20$ & $<0.02$ & $<0.02$ & - \\
Water (\%) & $20.54 \pm$ & $23.18 \pm$ & $24.89 \pm$ & $21.83 \pm$ & $25.89 \pm$ & 0.000 \\
& $0.11^{\mathrm{a}}$ & $0.38^{\mathrm{c}}$ & $0.77^{\mathrm{d}}$ & $0.19^{\mathrm{b}}$ & $0.36^{\mathrm{d}}$ & \\
Ash (\%) & $0.32 \pm$ & $0.40 \pm$ & $0.45 \pm$ & $0.48 \pm$ & $0.59 \pm$ & 0.000 \\
& $0.00^{\mathrm{a}}$ & $0.01^{\mathrm{b}}$ & $0.01^{\mathrm{c}}$ & $0.00^{\mathrm{d}}$ & $0.00^{\mathrm{e}}$ & \\
Fiber (\%) & $1.87 \pm$ & $1.53 \pm$ & $1.88 \pm$ & $1.44 \pm$ & $1.31 \pm$ & 0.003 \\
& $0.10^{\mathrm{b}}$ & $0.07^{\mathrm{a}}$ & $0.04^{\mathrm{b}}$ & $0.07^{\mathrm{a}}$ & $0.11^{\mathrm{a}}$ & \\
Brix $\left({ }^{\circ} \mathrm{Bx}\right)$ & $5.12 \pm$ & $8.45 \pm$ & $10.20 \pm$ & $12.50 \pm$ & $15.14 \pm$ & 0.000 \\
& $0.08^{\mathrm{a}}$ & $0.05^{\mathrm{b}}$ & $0.10^{\mathrm{c}}$ & $0.10^{\mathrm{d}}$ & $0.05^{\mathrm{e}}$ & \\
\hline The numbers followed by different superscript letters in the same row represent significantly different
\end{tabular}

values $(p \leq 0.05)$

From the results, it can be seen that the marmalade had high carbohydrates (70.52 \pm 0.46 $76.04 \pm 0.13 \%)$, proteins about $3.00 \pm 0.10-3.64 \pm$ $0.01 \%$. A very low fat found $<0.02 \%$ in all formulations since materials used in this product were vegetable and fruit, foodstuffs with very low or do not contain any fat. Then, the waters were about $20.54 \pm 0.11-25.89 \pm$ $0.36 \%$, ashes about $0.32 \pm 0.00-0.59 \pm 0.00 \%$, and fibers were about $1.44 \pm 0.07-1.88 \pm 0.04 \%$.

The Brix value seemed in line with the number of carrots added; more carrots caused a higher level of Brix. In this study, also Brix was different at $\alpha=0.05$, which means the carrot affected this parameter significantly. The Brix indicated the percentage of water-soluble solids in the liquid [16] and was dedicated as one of the essential criteria for liquid food. Brix may indicate the total sugar content due to a linear correlation between Brix and total sugar content. Thus, total sugar content could be calculated from the Brix [17]. The percentage of available sugar was associated with non-reducing sugar and reducing sugar value, Brix, stalk weight, gravity, invertase enzyme, and $\mathrm{pH}$ [18], [19]. Another study revealed that Brix significantly correlate to ash content; the greater Brix led to higher ash content, though the ash value also depends on material purity [20]. The same also proved in this study. We revealed a similar pattern between the value of ash and Brix.

\section{Antioxidant activity}

Antioxidant activity of carrots - navel marmalade was identified by DPPH methods. The 


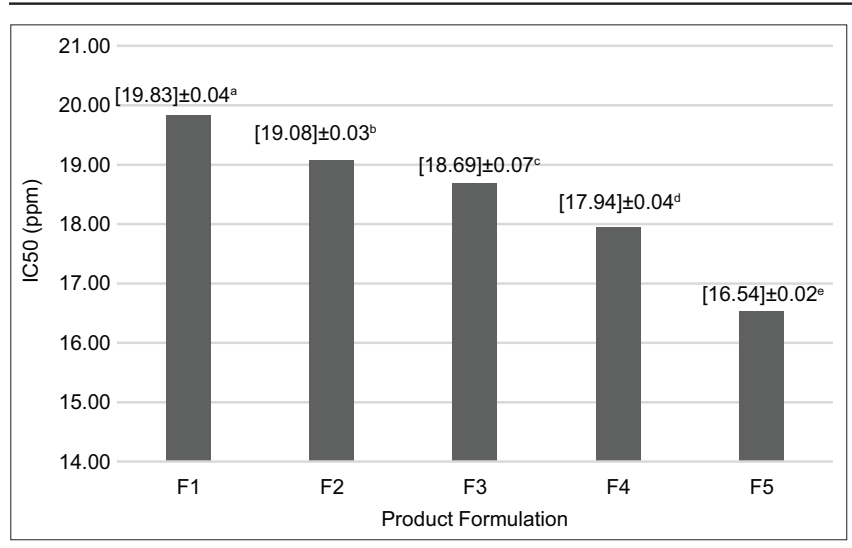

Figure 1: Antioxidant activities of carrot - navel orange marmalade, presented in IC50 (ppm). The numbers followed by different superscript letters represent significantly different values $(p \leq 0.05)$

result is displayed in Figure 1. All the products were measured and presented in the half-maximal inhibitory concentration $\left(\mathrm{IC}_{50}\right)$.

In this marmalade, the antioxidant of marmalade was obtained from the ingredients used in making the product, including navel orange, carrot, and lemon water. Those three are known as antioxidant sources. The navel orange and lemon water contain a high amount of Vitamin C, a powerful antioxidant compound, and carrot contributes to carotenoids, which also act as antioxidant compounds. However, the lemon water used in this study was aimed to improve the taste of the product. It was added as the same amount between formulations and declared as not a treatment factor of the product. Thus, lemon water cannot be a factor affecting differences in antioxidant products.

Besides, responsible for pigmentations, it seems carrots possessed antioxidant substances. The result showed that the more carrots added, the stronger the antioxidant activity was obtained. It can be seen from our result, the $\mathrm{IC}_{50}$ value of $\mathrm{F} 1 \quad(0 \%$ carrots) < F2 $(25 \%$ carrots $)<\mathrm{F} 3$ (50\% carrots) < F4 $(75 \%$ carrots $)<$ F5 $(100 \%$ carrots $)$. This value also statistically different each other at $\alpha=0.05$, means the carrot added at those level were influence the antioxidant of product. Carrots (Daucus carota) are a good source of natural antioxidants, such as carotenoids and phenolic compounds, vitamins, and flavonoids [21], [22]. Carotenoid has a polyene backbone consisting of a series of conjugated $\mathrm{C}=\mathrm{C}$ bonds as primary structural elements responsible for the pigmentation properties and their scavenging effect against free radicals [23]. Furthermore, the phenolic compound consisted may contribute to the freeradical scavenging effect of carrots. A study found that caffeoyl esters were identified as the main compound of phenolics content in freshly shredded carrots [24].

Asignificant amount of antioxidants are naturally present in orange. Some substances would contribute as the essential antioxidant elements consist of oranges, such as L-ascorbic acid, flavonoids, polyphenolic compounds, and carotenoids [25], [26]. A previous study revealed that Vitamin $\mathrm{C}$ is the most crucial antioxidant compound (65-90\%) of total antioxidants in orange juice [25].

In our product, carrot - navel orange marmalade, the peel of orange was added to build up the main marmalade characteristics. The orange peel evidence consists of some flavonoids substances. The isolated methanolic extract of orange peel mainly consisting of isolated flavonoid glycosides indicated an antioxidant potential. On quantitative high-pressure liquid chromatography analysis, the major flavonoid glycoside found in orange peel was hesperidin [27]. Therefore, together with hesperidin, Vitamin C contributes to the significant antioxidant from the orange navel in our marmalade products.

\section{Conclusion}

The addition of juice and shredded carrot into the orange marmalade (consisting of juice and shredded peel of navel orange) improves the organoleptic values, influences the proximate composition, and increases the Brix of products. Moreover, the more carrot added in orange marmalade may improve the antioxidant activities of marmalade and result in high antioxidant food products.

\section{References}

1. KarakayaS,EIS, TaşA.Antioxidantactivityofsomefoodscontaining phenolic compounds. Int J Food Sci Nutr. 2001;52(6):501-8. https://doi.org/10.1080/09637480020027000-6-6

PMid:11570016

2. Gutteridge JM, Halliwell B. Antioxidants in Nutrition, Health, and Disease. United Kingdom: Oxford University Press; 1994.

3. Kähkönen MP, Hopia AI, Vuorela HJ, Rauha JP, Pihlaja K, Kujala TS, et al. Antioxidant activity of plant extracts containing phenolic compounds. J Agric Food Chem. 1999;47(10):395462. https://doi.org/10.1021/jf990146I

PMid:10552749

4. Masriani M, Fadly D, Bohari B. a-Glucosidase inhibitory activity of ethanol extract obtained from dillenia suffruticosa and pycnarrhena cauliflora. J Glob Pharma Technol. 2020;12(2):881-7.

5. Fusco D, Colloca G, Lo Monaco MR, Cesari M. Effects of antioxidant supplementation on the aging process. Clin Interv Aging. 2007;2(3):377-87.

PMid:18044188

6. Dewi YS, Lestari OA, Fadly D. Identification phytochemicals and antioxidant activities of various fractions of methanol extracts from bark of Kulim tree (Scorodocarpus borneensis Becc.). Syst Rev Pharm. 2020;11(8):217-21.

7. Sofiana MS, Aritonang AB, Safitri I, Helena S, Nurdiansyah SI, 
Risko $\mathrm{R}$, et al. Proximate, phytochemicals, total phenolic content and antioxidant activity of ethanolic extract of eucheuma spinosum seaweed. Syst Rev Pharm. 2020;11(8):228-32.

8. Hasler CM. Functional foods: Their role in disease prevention and health memory, quicker reaction time, improved fetal health and promotion. Food Technol. 1998;52(2):57-62.

9. Association of Official Analytical Chemists. Official Methods of Analysis. $17^{\text {th }}$ ed., Vol. 2. United States: Association of Official Analytical Chemists; 2000. https://doi.org/10.5962/bhl.title.44636

10. Manzi P, Marconi S, Aguzzi A, Pizzoferrato L. Commercial mushrooms: Nutritional quality and effect of cooking. Food Chem. 2004;84(2):201-6. https://doi.org/10.1016/ s0308-8146(03)00202-4

11. Silva SA, de Queiroz DM, Pinto FA, Santos NT. Coffee quality and its relationship with Brix degree and colorimetric information of coffee cherries. Precis Agric. 2014;15:543-54. https://doi. org/10.1007/s11119-014-9352-y

12. Molyneux $P$. The use of the stable free radical diphenylpicrylhydrazyl (DPPH) for estimating antioxidant activity. Songklanakarin J Sci Technol. 2004;26(2):211-9.

13. Li N, Hu J, Wang S, Cheng J, Hu X, Lu Z, et al. Isolation and identification of the main carotenoid pigment from the rare orange muscle of the Yesso scallop. Food Chem. 2010;118(3):616-9. https://doi.org/10.1016/j.foodchem.2009.05.043

14. Ahmed EM, Dennison RA, Dougherty RH, Shaw PE. Flavor and odor thresholds in water of selected orange juice components. J Agric Food Chem. 1978;26(1):187-91. https://doi.org/10.1021/ jf60215a074

15. Shaw PE, Wilson CW. Importance of selected volatile components to natural orange, grapefruit, tangerine, and mandarin flavors. In: Nagy S, Attaway JA, editors. Citrus Nutrition and Quality, ACS Symposium Series. Vol. 143. Washington, DC: American Chemical Society; 1980. p. 167-90. Available from: https://www.pubs.acs.org. [Last accessed on 2020 Jun 21]. https://doi.org/10.1021/bk-1980-0143.ch009

16. Türkmen İ, Ekşi A. Brix degree and sorbitol/xylitol leve of authentic pomegranate (Punica granatum) juice. Food Chem. 2011;127(3):1404-7. https://doi.org/10.1016/j. foodchem.2010.12.118 PMid:25214145

17. Ma ZH, Li D, Ning XB. Study on brix degree, total sugar content and their relationship in the juice of sweet sorghum stem. J Shenyang Agric Univ. 1992;23(3):178-91.

18. Mallikarjun $\mathrm{H}$, Khanure $\mathrm{S}$, Kachapur $\mathrm{M}$. Correlation and path analysis for juice quality parameters in sweet sorghum genotypes. Madras Agric J. 1999;85(3-4):207-8.

19. Ashwathama V, Channappagoudar B, Chetti M, Nawalagatti C Hiremath S. Studies on the Biophysical, Yield and Quality Characters in Sweet Sorghum Genotypes, Beijing, China; 1997. p. 293-7.

20. King RH. A degree brix-total solid relationship. Ind Eng Chem Anal Ed. 1931;3(3):230-2

21. Prakash S, Jha SK, Datta N. Performance evaluation of blanched carrots dried by three different driers. J Food Eng. 2004;62(3):30513. https://doi.org/10.1016/s0260-8774(03)00244-9

22. Zhang D, Hamauzu Y. Phenolic compounds and their antioxidant properties in different tissues of carrots (Daucus carota L.) J Food Agric Environ. 2004;2:95-100

23. Phillip D, Hobe S, Paulsen $H$, Molnar P, Hashimoto $H$, Young AJ. The binding of Xanthophylls to the bulk light-harvesting complex of photosystem II of higher plants: A specific requirement for carotenoids with a 3 -hydroxy- $\beta$-end group. J Biol Chem. 2002;277(28):25160-9. https://doi.org/10.1074/jbc.m202002200

24. Babic I, Amiot MJ, Nguyen-The C, Aubert S. Changes in phenolic content in fresh ready-to-use shredded carrots during storage. J Food Sci. 1993;58(2):351-6. https://doi. org/10.1111/j.1365-2621.1993.tb04273.x

25. Gardner PT, White TA, McPhail DB, Duthie GG. The relative contributions of Vitamin $\mathrm{C}$, carotenoids and phenolics to the antioxidant potential of fruitjuices. Food Chem. 2000;68(4):471-4. https://doi.org/10.1016/s0308-8146(99)00225-3

26. Rapisarda $P$, Tomaino $A$, Lo Cascio $R$, Bonina $F$, de Pasquale A, Saija A. Antioxidant effectiveness as influenced by phenolic content of fresh orange juices. J Agric Food Chem. 1999;47(11):4718-23. https://doi.org/10.1021/jf990111।

27. Kanaze FI, Termentzi A, Gabrieli C, Niopas I, Georgarakis M, Kokkalou E. The phytochemical analysis and antioxidant activity assessment of orange peel (Citrus sinensis) cultivated in Greece-Crete indicates a new commercial source of hesperidin. Biomed Chromatogr. 2009;23(3):239-49. https://doi. org/10.1002/bmc.1090

PMid:18823075 